\title{
Effect of 6-Aminohexanoic Acid Released from Its Aluminum Tri-Polyphosphate Intercalate (ATP-6-AHA) on the Corrosion Protection Mechanism of Steel in 3.5\% Sodium Chloride Solution
}

\author{
Chaymae Hejjaj ${ }^{1,2, *}$, Ahmed Ait Aghzzaf ${ }^{3}$, Nico Scharnagl ${ }^{4}{ }^{(D}$, Mohammed Makha $^{1}$ (D), Mouad Dahbi ${ }^{1}$, \\ Mikhail L. Zheludkevich ${ }^{4,5}$, Rachid Hakkou ${ }^{2,6}$ and Christian B. Fischer 1,7,*(D)
}

1 Materials Science, Energy and Nano-Engineering Department, University Mohammed VI Polytechnic (UM6P), Lot 660, Hay Moulay Rachid, Ben Guerir 43150, Morocco; Mohammed.MAKHA@um6p.ma (M.M.); mouad.dahbi@um6p.ma (M.D.)

2 IMED-Lab, Faculty of Science and Technology, Cadi Ayyad University (UCA), Marrakesh BP549, Morocco; rachid.hakkou@um6p.ma

3 Laboratoire des Sciences Appliquées et Didactique (LaSAD), Ecole Normale Supérieure, Université Abdelmalek Essaâdi, Tetouan 93020, Morocco; a.aitaghzzaf@uae.ac.ma

4 Institute of Surface Science, Helmholtz-Zentrum Hereon GmbH, Max-Planck-Straße 1, 21502 Geesthacht, Germany; nico.scharnagl@hereon.de (N.S.); Mikhail.Zheludkevich@hereon.de (M.L.Z.)

check for updates

Citation: Hejjaj, C.; Aghzzaf, A.A.; Scharnagl, N.; Makha, M.; Dahbi, M.; Zheludkevich, M.L.; Hakkou, R.; Fischer, C.B. Effect of 6-Aminohexanoic Acid Released from Its Aluminum Tri-Polyphosphate Intercalate (ATP-6-AHA) on the Corrosion Protection Mechanism of Steel in 3.5\% Sodium Chloride Solution. Corros. Mater. Degrad. 2021, 2,666-677. https://doi.org/10.3390/ cmd 2040036

Academic Editor: Daniel John Blackwood

Received: 31 August 2021

Accepted: 9 November 2021

Published: 12 November 2021

Publisher's Note: MDPI stays neutral with regard to jurisdictional claims in published maps and institutional affiliations.

Copyright: (C) 2021 by the authors Licensee MDPI, Basel, Switzerland. This article is an open access article distributed under the terms and conditions of the Creative Commons Attribution (CC BY) license (https:// creativecommons.org/licenses/by/ $4.0 /$ )
5 Faculty of Engineering, Kiel University, Kaiserstraße 2, 24143 Kiel, Germany

6 Mining Environment and Circular Economy Program (EMEC), Mohammed VI Polytechnic University (UM6P), Lot 660, Hay Moulay Rachid, Ben Guerir 43150, Morocco

7 Department of Physics, University Koblenz-Landau, 56070 Koblenz, Germany

* Correspondence: chaymae.hejjaj@um6p.ma (C.H.); chrbfischer@uni-koblenz.de (C.B.F.); Tel.: +212-5-25-07-3014 (C.H.); +49-261-287-2345 (C.B.F.)

\begin{abstract}
A new corrosion inhibitor called ATP-6-AHA was elaborated, and its inhibition action on $\mathrm{S} 235$ low carbon steel in $3.5 \%$ sodium chloride $(\mathrm{NaCl})$ was investigated using gravimetry, potentiodynamic polarization (PP), and electrochemical impedance spectroscopy (EIS). The release of ecofriendly 6-aminohexanoic acid (6-AHA) from its established aluminum tri-polyphosphate intercalate (ATP-6-AHA) is investigated using electrochemical and surface characterization techniques such as X-ray diffraction (XRD) and X-ray fluorescence (XRF). The results revealed that ATP-6-AHA is a good inhibitor, with an inhibition efficiency of approximately $70 \%$. The efficiency is related to the passivation of a steel surface by a phosphate protective layer due to the synergistic effect of 6-AHA, as confirmed by a steel surface analysis conducted using X-ray photoelectron spectroscopy (XPS) and scanning electron microscopy (SEM). This study suggests that the intercalation of 6-AHA as a sustainable organic molecule within the interlayer spaces of aluminum tri-polyphosphate can well serve as a good flaky inhibitor for protecting S235 low-carbon steel from corrosion in 3.5\% NaCl.
\end{abstract}

Keywords: carbon steel; polyphosphate; corrosion; anodic inhibition; XPS

\section{Introduction}

Carbon steel is widely used in several industrial applications due to its outstanding mechanical properties and low cost [1]. However, this material is subject to corrosion in aggressive environments, such as marine media [2,3]. One method to decrease the rate of iron dissolution that is frequently applied is the use of corrosion inhibitors [4-6]. Among the non-toxic compounds that are, aluminum dihydrogen tri-polyphosphate (ATP) has been shown to be a good candidate for steel [7]. However, ATP has high acidity and low solubility, affecting the long-term storage stability of the coated systems [8]. Therefore, a large number of studies have been performed to modify this layered phosphate compound by introducing different additives [7]. Among others, 6-aminohexanoic acid (6-AHA) is an 
organic, aqueous soluble molecule comprising polar nitrogen and oxygen atoms as well as double bonds in its molecular structure and has been tested as a corrosion inhibitor for mild steel in hydrochloride solution, showing enhanced corrosion protection, as reported by M. Abdeli et al. [9]. In addition, the organic molecule of 6-aminohexanoic acid (6-AHA) has been intercalated into the interlayer space of layered ATP, as recently shown by some of the authors [10]. In this work, ATP and ATP-6-AHA were characterized by different characterization techniques (XRD, TGA (thermogravimetric analysis), SEM, Infrared and Raman spectroscopy). The interlayer space of ATP was expanded by $10.1 \AA$, with the 6AHA planes arranged in bilayers [10]. No investigation has been conducted regarding the deintercalation of 6-AHA from the ATP-6-AHA hybrid material nor on the contribution of the 6-amino hexanoic acid (6-AHA) to the protection mechanism of S235 low-carbon steel.

For many years, ATP was mainly used as an anticorrosive additive in coatings and was preferential to the less environmentally friendly lead and chromium alternatives. Several works have been published in this sense. An inorganic coating that was created by combining chemically bonded phosphate ceramic (CBPC) binder and aluminum tripolyphosphate (ATP) pigment was designed and prepared for the anti-corrosion treatment of steel, showing enhanced corrosion protection [11]. X. Lu et al. showed that the protective performance of a Mg-rich primer on an AZ91D magnesium alloy was greatly improved with the addition of aluminum di-hydrogen tripolyphosphate pigment into the primer [12].

Song et al. evaluated the influence of aluminum di-hydrogen tripolyphosphate on the protective behavior of an acrylic water-based paint applied to rusty steels. The electrochemical results obtained using an EIS of scratched steel for $500 \mathrm{~h}$ of immersion in $3.5 \% \mathrm{NaCl}$ solution showed evidence of good anticorrosive performance, with no rust, blisters, flakes, or cracks occurring on the coating compared to the epoxy antirust coatings. The LEIS (local electrochemical impedance spectroscopy) measurements performed in $3.5 \% \mathrm{NaCl}$ showed that the coatings exhibited electrochemical activity at the beginning of immersion; as such, the mechanism of protection is due to an iron phosphate layer, leading to an increase in the coating resistance [13].

For ATP-6-AHA, further studies are needed to explain the inhibition mechanism that is induced by the release of 6-AHA into the corrosive medium in order to promote the formation of an iron phosphate film. As a consequence, the purpose of the current work is to confirm the deintercalation of 6-AHA after electrochemical impedance spectroscopy (EIS) testing using X-ray diffraction (XRD) and X-ray fluorescence (XRF).

We have already tested the application of this material in our previous work using $0.1 \mathrm{M}(\mathrm{NaCl})$ medium, but we did not conduct an extensive investigation for higher concentrations [10]. A 3.5\% NaCl solution has been used as an electrolyte in several corrosion inhibitor studies [14,15], which to some extent, simulate an actual corrosive solution. In view of the above observations and as a continuation of our work on understanding the protection mechanism of ATP-6-AHA, we report a more in-depth study to examine the corrosion-inhibiting ability of this new phosphate compound in an aggressive environment, such as in a $3.5 \% \mathrm{NaCl}$ aerated solution. The inhibition efficiency of the aluminum tri-polyphosphate intercalated 6-aminohexanoic acid (ATP-6-AHA) was investigated by means of the gravimetric method and through electrochemical measurements using open circuit potential (OCP), potentiodynamic polarization (PP), and EIS and showed an enhanced corrosion resistance for S235 low-carbon steel in the presence of ATP-6-AHA, with an inhibition efficiency of approximately $70 \%$. The protection mechanism was evaluated using X-ray photoelectron spectroscopy (XPS) and a scanning electron microscope (SEM). It was in this way that a protective layer was deposited onto steel surface, which occurred as a result of the synergistic effect of the released 6-AHA from ATP-6-AHA with aluminum phosphate anions. 


\section{Experimental}

\subsection{ATP-6-AHA Synthesis Procedure}

The necessary precursor, aluminum dihydrogen tri-polyphosphate $\left(\mathrm{AlH}_{2} \mathrm{P}_{3} \mathrm{O}_{10} \cdot 2 \mathrm{H}_{2} \mathrm{O}\right)$, was synthesized according to our previous protocol and according to Rishi et al. [10,13]. Alumina oxide and phosphoric acid (mole ratio $\mathrm{P}_{2} \mathrm{O}_{5} / \mathrm{Al}_{2} \mathrm{O}_{3}$ is $3: 1$ ) were mixed until the mixture became viscous. The slurry was then transferred into a reacting furnace and was heated up to $240{ }^{\circ} \mathrm{C}$ for $24 \mathrm{~h}$. The obtained solid was taken out of the furnace and was washed many times using deionized water until the filtrate became clear and had an acidic $\mathrm{pH} \sim 3$; it was subsequently dried and was finally ground using an agate mortar into fine powders. The intercalation of 6-aminohexanoic acid $\left(\mathrm{NH}_{2}\left(\mathrm{CH}_{2}\right)_{5} \mathrm{CO}_{2} \mathrm{H}, 99 \%\right.$, Sigma Aldrich, Taufkirchen, Germany), was carried out by mixing $0.5 \mathrm{~g}$ of ATP with 6-aminohexanoic acid $(0.5 \mathrm{M})$. The slurry was stirred at room temperature (RT) for $24 \mathrm{~h}$. The obtained compound was filtered, washed with double distilled water, centrifuged, and dried under ambient conditions for $24 \mathrm{~h}$ [10].

\subsection{Characterizations Methods}

After the electrochemical tests, ATP, ATP-6-AHA, and its deintercalated form 6-AHAATP were characterized by means of X-ray diffraction (XRD) using a Bruker (D8, Karlsruhe, Germany) equipped with a copper cathode ( $k=0.154 \mathrm{~nm})$ at a $2 \theta$ range from 3 to $70^{\circ}$ and at $0.01(2 \theta)$ steps. The elemental analysis for phosphorus $(\mathrm{P})$ and aluminum (Al) wasconducted using X-ray fluorescence (XRF) (Epsilon 4, Malvern Panalytical, Malvern, UK).

XPS steel surface analysis was performed by a KRATOS AXIS Ultra DLD (Kratos Analytical, Manchester, UK) assembled with a monochromatic $\mathrm{Al} \mathrm{K} \alpha$ anode performing at $15 \mathrm{kV}(225 \mathrm{~W})$. For the survey spectra, a pass energy of $160 \mathrm{eV}$ was used, while for the region spectra, it was $40 \mathrm{eV}$. The investigated area was $700 \mu \mathrm{m} \times 300 \mu \mathrm{m}$. For all of the steel samples, charge neutralization was necessary. The evaluation and validation of the data were achieved using the CASA-XPS software (software version 2.3.18, Casa Software Ltd., Manchester, UK). The spectra were calibrated by adjusting the C1s signal to $284.5 \mathrm{eV}$. For the deconvolution of the region files, background subtraction (linear or Shirley) was performed before calculation.

The surface morphology of the S235 steel surface in sodium chloride with the ATP6-AHA inhibitor was examined using a scanning electron microscope (TESCAN Vega TC X64, Brno, Czech Republic) equipped with an energy dispersive X-ray (EDX) spectrometer for the elemental composition analysis of the samples from eumeX (XRFSystems, Heidenrod, Germany).

\subsection{Materials and Low Carbon Steel Surface Preparation}

The chemical composition by weight \% of the low-carbon steel (S235 (E24), El Jadida, Morocco) used in this study was as follows: S: 0.020, P: 0.017, Mn: 0.457, Cu: 0.301, Si: 0.114, Mo: 0.023, Ni: 0.076, C: 0.111, and Fe as balance [10]. Before each electrochemical experiment, the exposed steel area was polished with different grades of emery papers $(120,800$, and 2400 grit), rinsed with distilled water, and degreased with acetone before being transferred to the measurement cell. The corrosive $3.5 \% \mathrm{NaCl}$ solution was prepared using analytical reagent-grade chemicals (sodium chloride, 99\%, SOLVACHIM, Germany) and distilled water in order to obtain a blank solution and a $0.18 \mathrm{~g} / \mathrm{L}$ concentration of the ATP-6-AHA phosphate-based compound for the ATP-6-AHA solution.

\subsection{Corrosion Tests}

The gravimetric method is an effective non-electrochemical technique that requires the exposure of the steel samples in the solution under study for a specific time period. The corrosion rate (CR) expressed in $\mathrm{mm} / \mathrm{y}$ (Equation (1)) of the current $\mathrm{S} 235$ steel samples was evaluated after $20 \mathrm{~h}$ of immersion in $3.5 \% \mathrm{NaCl}$ with and without ATP-6-AHA [16]. 


$$
\mathrm{CR}\left(\frac{\mathrm{mm}}{\mathrm{y}}\right)=\frac{87.6 \cdot \mathrm{W}}{\mathrm{a} \cdot \mathrm{t} \cdot \mathrm{D}}
$$

where (W) is the weight loss of the S235 steel specimen, (a) is the exposed surface area of the specimen, $(t)$ is the immersion time $(20 \mathrm{~h})$, and (D) is the 5235 steel density.

Electrochemical tests were performed in a three-electrode glass cell at room temperature $\left(25^{\circ} \mathrm{C}\right)$. A platinum counter electrode and a saturated calomel reference electrode (SCE) were used in all of the electrochemical experiments performed using a SP150 BioLogic potentiostat/galvanostat. The corrosion potential was recorded during $20 \mathrm{~h}$ of immersion time, and the polarization plots were made with and without ATP-6-AHA at a scanning speed of $1 \mathrm{mV} \mathrm{s}^{-1}$. Impedance plots were acquired using $10 \mathrm{mV}$ (RMS) sinusoidal perturbation in the frequency range from $10^{5}$ to $10^{-2} \mathrm{~Hz}$, with nine points per frequency decade. The EIS measurements were executed after $20 \mathrm{~h}$ of immersion time.

\section{Results}

\subsection{Chemical Composition}

The XRD spectra of ATP, ATP-6-AHA, and the deintercalated form 6-AHA-ATP are shown in Figure 1. The layered structure of the ATP was confirmed by the presence of the intense (001) peak of the $\mathrm{AlH}_{2} \mathrm{P}_{3} \mathrm{O}_{10} \cdot 2 \mathrm{H}_{2} \mathrm{O}$ (ref code: 96-710-0708) phase at $2 \theta=11.2$, corresponding to a basal spacing of $0.79 \mathrm{~nm}$, and consistent with previous data reported by Rishi et al. [17]. The increase in the basal distance of approximately $1 \mathrm{~nm}$ in the ATP-6-AHA diffractogram can be attributed to an expansion of the interlayer spacing for the host ATP through the intercalation of the organic 6-AHA. A new phase appears after intercalation, with a $\mathrm{d}_{001}$ basal spacing of $1.79 \mathrm{~nm}$. According to the XRD pattern of ATP-6-AHA after the EIS test, after the deintercalation [10], the upper spectrum in Figure 1 shows a large decrease in the (001) characteristic peak of ATP-6-AHA, with the appearance of a new phase of $\mathrm{Na}_{2} \mathrm{AlP}_{3} \mathrm{O}_{10} \cdot 4 \mathrm{H}_{2} \mathrm{O}$ (ref code: 00-036-0262), which clearly confirms the release of 6-AHA from ATP-6-AHA during the EIS test in sodium chloride.

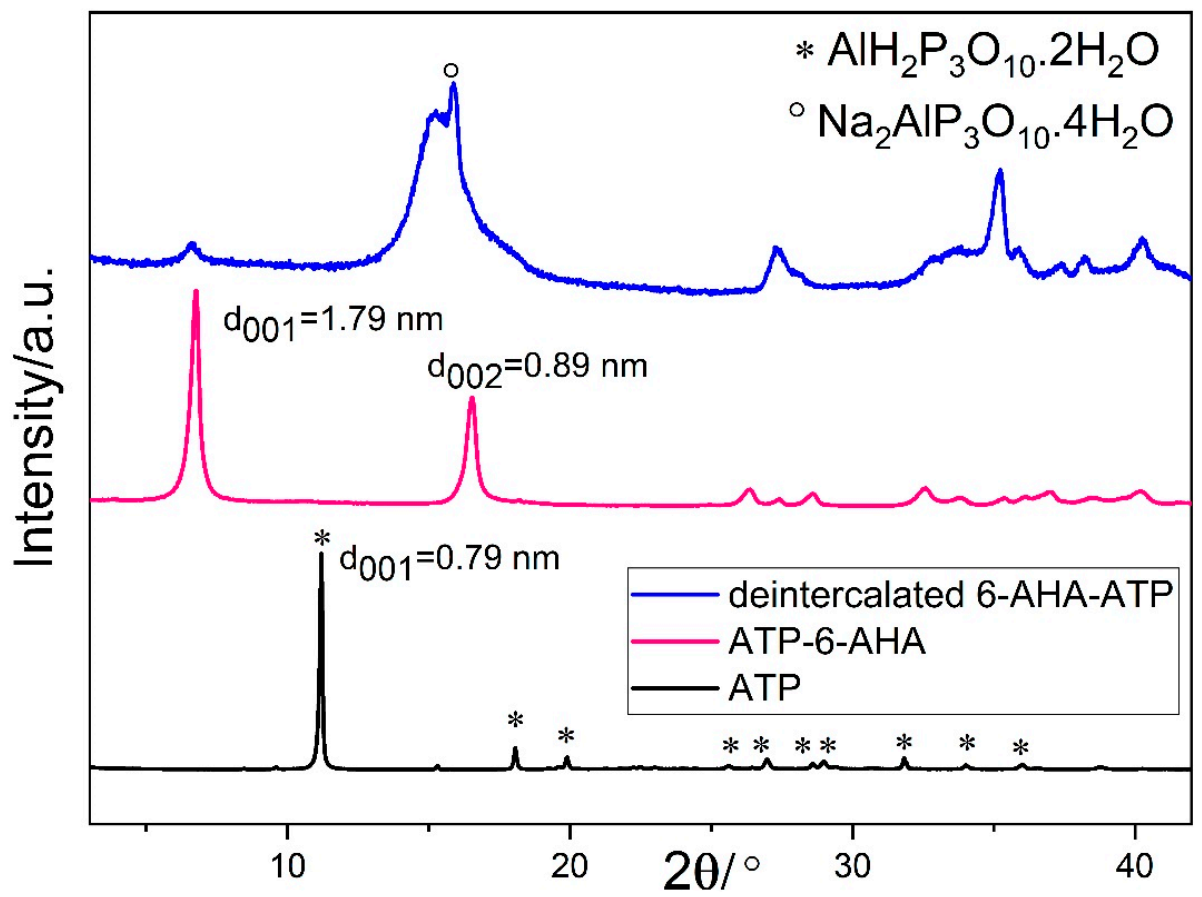

Figure 1. X-ray diffraction patterns of ATP (bottom), ATP-6-AHA (middle), and its deintercalated form $\mathrm{Na}_{2} \mathrm{AlP}_{3} \mathrm{O}_{10} \cdot 4 \mathrm{H}_{2} \mathrm{O}$ (top). 
The chemical composition of ATP, ATP-6-AHA, and the deintercalated form was determined by XRF spectroscopy. The chemical composition in Table 1 shows that phosphates and alumina $\left(\mathrm{Al}_{2} \mathrm{O}_{3}\right)$ are the major chemical constituents of ATP. This composition decreases after the intercalation of 6-AHA; moreover, a larger decrease was noticed for the deintercalated form.

Table 1. Phosphate and alumina composition of ATP, ATP-6-AHA, and its deintercalated form using the XRF technique.

\begin{tabular}{cccc}
\hline & ATP & ATP-6AHA & Deintercalated Form (6-AHA-ATP) \\
\hline Phosphate & 50.05 & 44.84 & 29.05 \\
Alumina & 11.17 & 11.05 & 8.65 \\
\hline
\end{tabular}

\subsection{Gravimetric and Electrochemical Measurements}

The corrosion tests showed that the CR in the blank sodium chloride solution is $0.21 \mathrm{~mm} /$ year. This rate decreases to $0.072 \mathrm{~mm} /$ year after the addition of ATP-6-AHA with a concentration of $0.18 \mathrm{~g} / \mathrm{L}$. The inhibiting effect of ATP-6-AHA on the corrosion of S235 low-carbon steel was determined by evaluating the inhibition efficiency $\eta(\%)$ according to Equation (2):

$$
\eta(\%)=\frac{\mathrm{CR}(\text { blank })-\mathrm{CR}(\mathrm{ATP}-6-\mathrm{AHA})}{\mathrm{CR}(\mathrm{ATP}-6-\mathrm{AHA})} \times 100
$$

where $\mathrm{CR}$ (blank) and $\mathrm{CR}(\mathrm{ATP}-6-\mathrm{AHA})$ denote the corrosion rate calculated using the gravimetric method in the $3.5 \% \mathrm{NaCl}$ solution with and without ATP-6-AHA.

Figure 2a shows the evolution of the S235 low-carbon steel potential as a function of immersion time in the $3.5 \% \mathrm{NaCl}$ solution with and without ATP-6-AHA. The curves reveal that the presence of ATP-6-AHA in the corrosive medium increases the corrosion potential, which is approximately $70 \mathrm{mV}$ higher than that in blank solution.
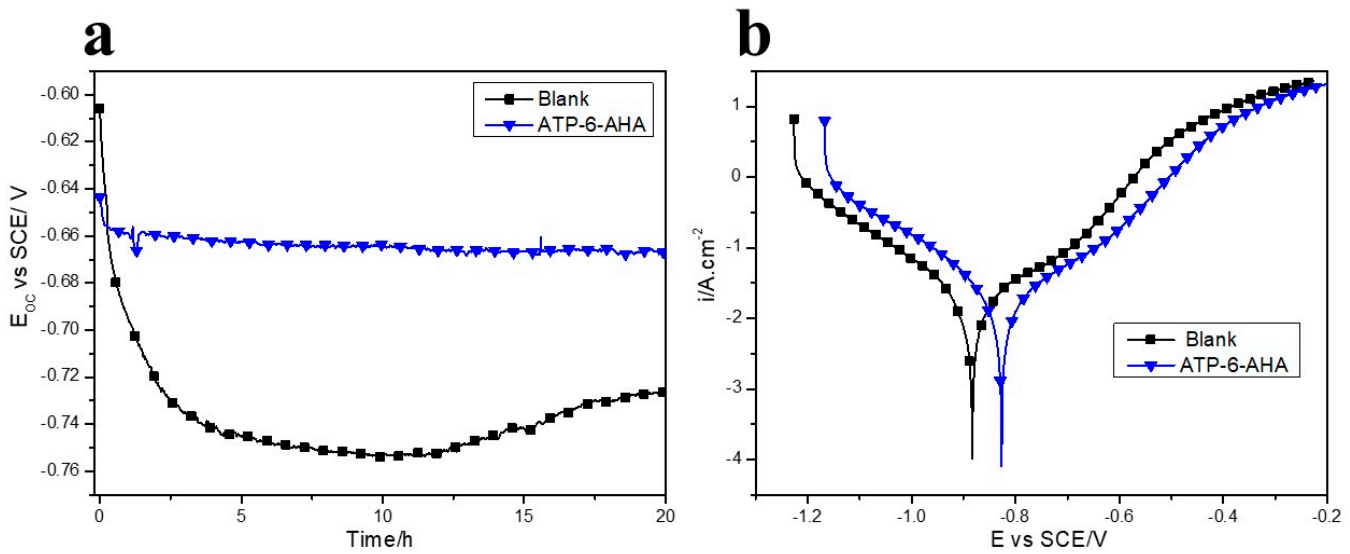

Figure 2. (a) Potential and (b) polarization curves of S235 low-carbon steel after $20 \mathrm{~h}$ of immersion time in $3.5 \% \mathrm{NaCl}$ with (triangles) and without ATP-6-AHA (squares).

After the S235 steel/electrolyte interface had been stabilized for $20 \mathrm{~h}$ in the presence of ATP-6-AHA, the polarization curves in Figure $2 b$ show that the corrosion potential of the steal increased by nearly $70 \mathrm{mV}$ compared to the blank one. The current density decreased from $18.5 \mu \mathrm{A} \cdot \mathrm{cm}^{-2}$ for the blank one compared to $6.2 \mu \mathrm{A} \cdot \mathrm{cm}^{-2}$ for the ATP-6AHA solution (Table 2), which corresponds to an inhibition efficiency of $66 \%$. The cathodic current increased slightly as a result of the inhibitor addition. This could be related to the decrease of the $\mathrm{pH}$ of the electrolyte accelerating the hydrogen evolution kinetics. These results indicate that ATP-6-AHA phosphate mainly prevents the anodic reaction of the corrosion process. 
Table 2. Calculated data obtained from the potentiodynamic polarization curves of low carbon steel in $3.5 \% \mathrm{NaCl}$ solution without and with the addition of ATP-6-AHA.

\begin{tabular}{ccccc}
\hline & E $_{\text {corr }} / \mathbf{V}$ vs. SCE & $\mathbf{i}_{\text {corr }} / \mu \mathbf{A} \mathbf{~ c m}^{-2}$ & CR $(\mathbf{m m} / \mathbf{y})$ & $\eta / \%$ \\
\hline Blank & $-883 \pm 11$ & $18.5 \pm 1.3$ & 0.213 & - \\
ATP-6-AHA & $-817 \pm 15$ & $6.2 \pm 2.1$ & 0.072 & 66 \\
\hline
\end{tabular}

The Bode spectra in Figure 3 do not show differences at high frequencies beyond $10^{3} \mathrm{~Hz}$, indicating similar impedance behavior due to the resistance of the solution. The spectra are characterized by two well-defined relaxation processes. The time constant at about $1-10 \mathrm{~Hz}$ is related to the charge transfer process and the double-layer capacitance, while the low-frequency relaxation most probably originates from the diffusion limitations. Nevertheless, the impedance modulus measured at low frequencies $\left(10^{-2} \mathrm{~Hz}\right)$ and that is associated with the polarization resistances $R$ p discloses that the presence of ATP-6-AHA makes it possible to multiply the polarization resistance of the steel surface by a factor of 2 .

The gravimetric and electrochemical measurements revealed an enhanced corrosion inhibition performance of ATP-6-AHA, which can be attributed to the formation of a porous film composed of iron phosphate, as shown by the XPS and SEM steel surface analysis below.

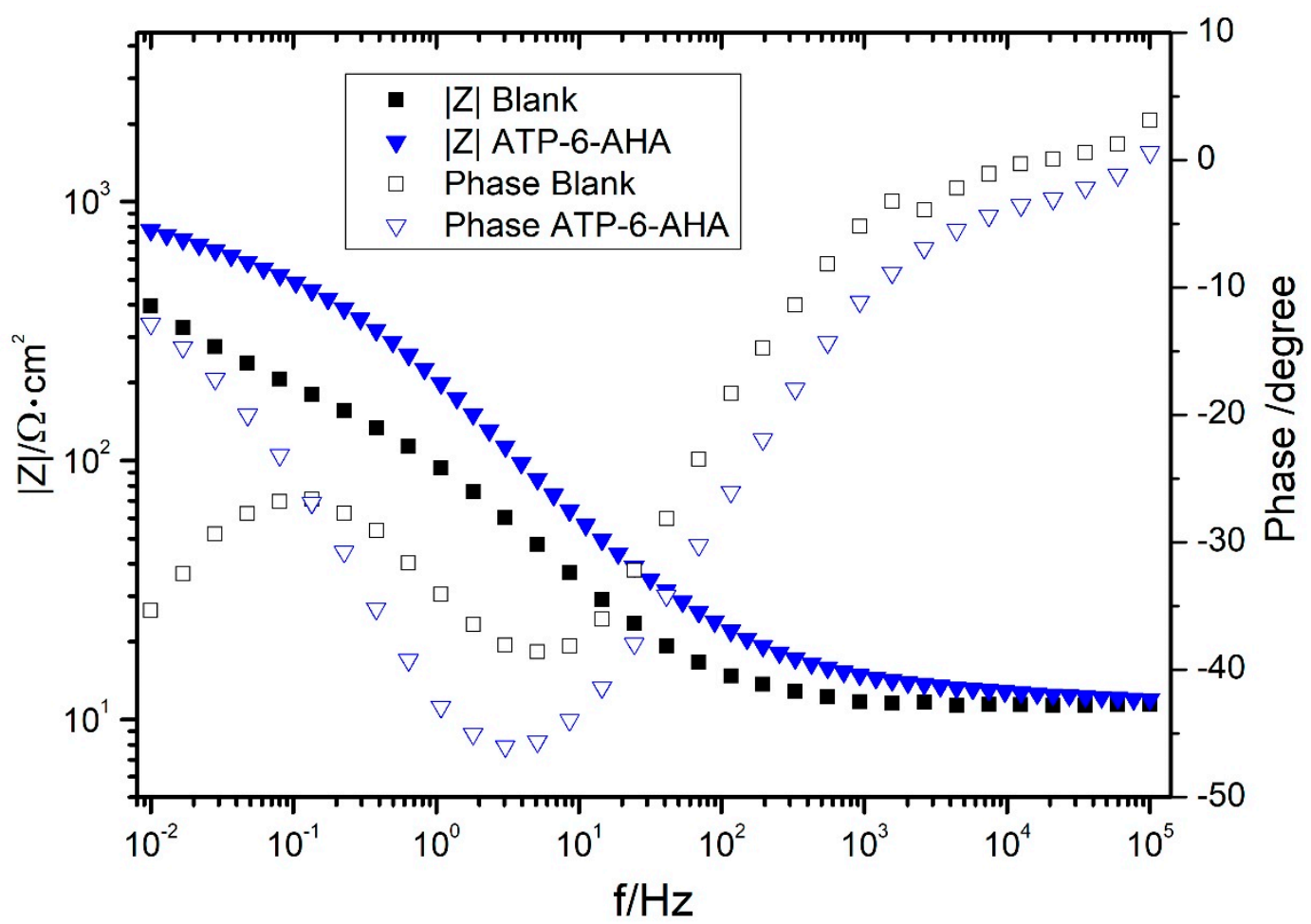

Figure 3. Bode diagram of S235 low carbon steel after $20 \mathrm{~h}$ of immersion time in $3.5 \% \mathrm{NaCl}$ with and without ATP-6-AHA.

\subsection{XPS Analysis of Corrosion Products}

A detailed XPS investigation on each exposed S235 low-carbon steel surface was conducted. Figure 4 presents the whole survey, from 0 to $1300 \mathrm{eV}$ of steel without inhibitor to the $\mathrm{S} 235$ steel surface after immersion tests in the $3.5 \% \mathrm{NaCl}$ solution using ATP-6-AHA taking place over the course of five days. From the XPS spectrum in (Figure 4a), the main elements in the rust matrix for the steel surface without inhibitor are $\mathrm{Fe}, \mathrm{O}, \mathrm{C}$, and $\mathrm{Na}$. The peaks of Fe 2p appear in the region between 709 to $734 \mathrm{eV}$. As shown in Figure 5, the electron binding energy centers of $\mathrm{Fe} 2 \mathrm{p}_{3 / 2}$ and $\mathrm{Fe} 2 \mathrm{p}_{1 / 2}$ at 711.3 and $728 \mathrm{eV}$, respectively, fulfill the standard data of $\mathrm{Fe}_{2} \mathrm{O}_{3}$ [15]. The binding energy of $719 \mathrm{eV}$ is a shakeup with 
an associated $\mathrm{Fe} 2 \mathrm{p}_{3 / 2}$ satellite peak, which is a fingerprint of the electronic structure of $\mathrm{Fe}^{3+}[18,19]$. Furthermore, another satellite peak can be observed at $734 \mathrm{eV}$, which can be assigned to $\mathrm{Fe} 2 \mathrm{p}_{1 / 2}$ [20].
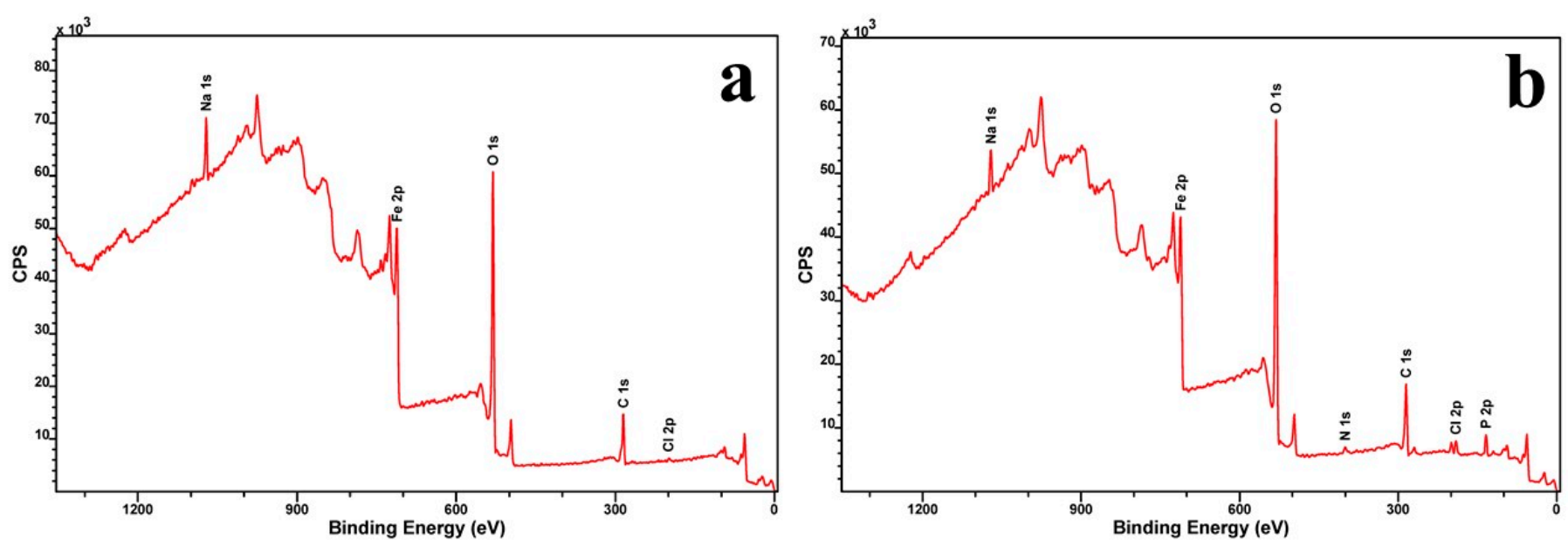

Figure 4. XPS surveys of S235 low-carbon bare steel after five days of immersion in $3.5 \% \mathrm{NaCl}$ (a) for blank solution and (b) a solution with ATP-6-AHA.
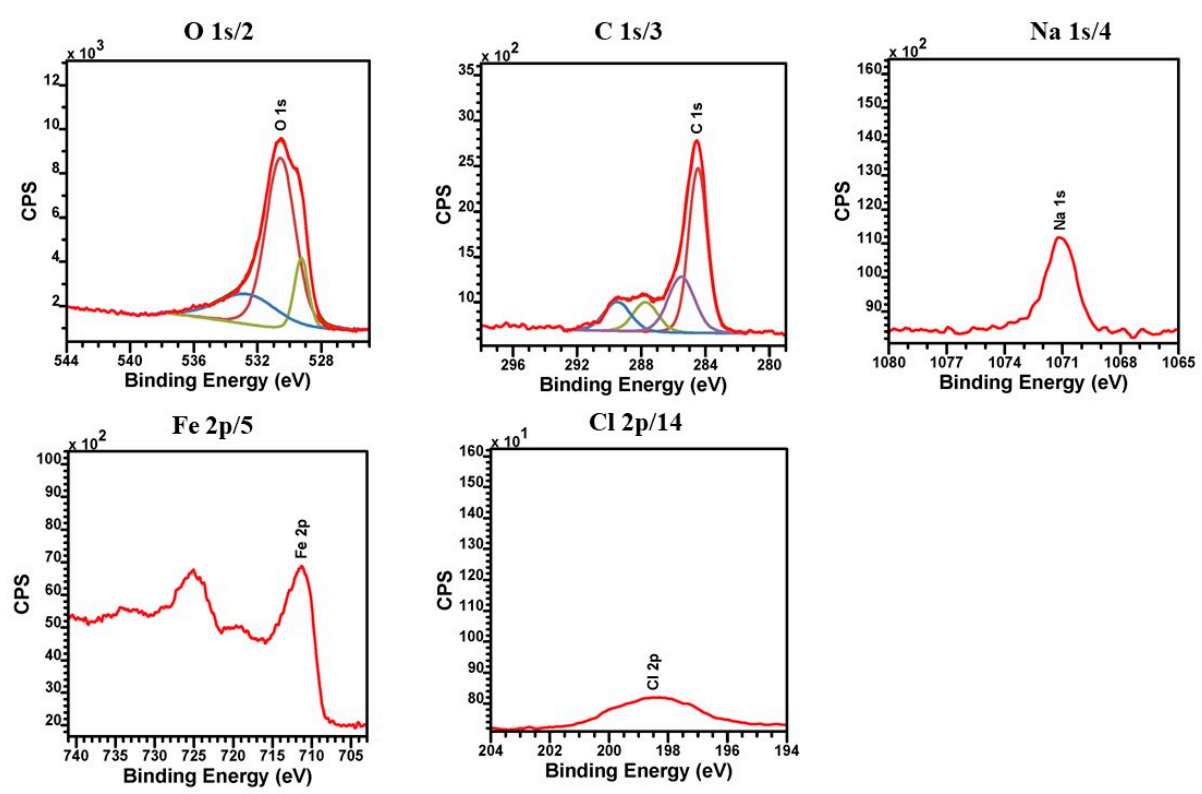

Figure 5. High resolution $\mathrm{O} 1 \mathrm{~s}, \mathrm{C} 1 \mathrm{~s}, \mathrm{Na} 1 \mathrm{~s}, \mathrm{Fe} 2 \mathrm{p}$, and $\mathrm{Cl} 2 \mathrm{p}$ XPS peaks obtained on the surface of the $\mathrm{S} 235$ low-carbon steel substrate after five days of treatment in $3.5 \% \mathrm{NaCl}$ solution (colors indicate typical bonds, details in the text).

The presence of iron oxides and hydroxides can be confirmed from the $\mathrm{O} 1 \mathrm{~s}$ spectra (Figure 5). The oxygen signal is composed of three peaks. The first peak at $530.5 \mathrm{eV}$ (green, Figure 5) is assigned to iron oxides [20], while the second at $531.5 \mathrm{eV}$ (brown, Figure 5) is due to the presence of the $\left(\mathrm{OH}^{-}\right)$ions attributed to the iron oxy-hydroxides $\mathrm{FeO}(\mathrm{OH})$ [21], as verified by the XRD of the corroded S235 steel surface. The third peak at $533.5 \mathrm{eV}$ (blue, Figure 5) has a lower intensity in comparison, which can be assigned to the adsorbed water molecules [21]. The carbon line (C 1s) has four main peaks, as described in Figure 5. The dominant peak was assessed at a binding energy of $285 \mathrm{eV}$ (brown, Figure 5). The peak observed at $286 \mathrm{eV}$ (purple, Figure 5), known as single bonded carbon C-C, is generally related to the contaminants that are common in XPS analysis due to the hydrocarbons that are present in the environment [22]. However, the two peaks observed at higher energy 
$(\sim 289 \mathrm{eV})$ (green and blue, Figure 5) correspond to carbon double-bonded oxygen $\mathrm{C}=\mathrm{O}$ [23]. Moreover, the Na 1s spectrum could be fitted to one component at $1071.1 \mathrm{eV}$ that is related to the presence of $\mathrm{Na}^{+}$-ions [24].

The chemical composition and oxidation states of a low-carbon steel surface with ATP6-AHA are shown in Figure 6, which demonstrates core level peaks for Fe 2p, O 1s, P 2p, $\mathrm{C} 1 \mathrm{~s}$, and $\mathrm{N} 1 \mathrm{~s}$. The Fe $2 \mathrm{p}$ spectrum in Figure 6 shows the respective binding energies of 712 and $719 \mathrm{eV}$ for $\mathrm{Fe} 2 \mathrm{p}_{3 / 2}$ and $\mathrm{Fe} 2 \mathrm{p}_{1 / 2}$ along with their respective satellite contributions at 719 and $734 \mathrm{eV}$, which can be assigned to $\mathrm{Fe}_{2} \mathrm{O}_{3}$ [21] and $\mathrm{FePO}_{4}$ [20], respectively. The high-resolution spectrum of $\mathrm{O} 1 \mathrm{~s}$ exhibits three peaks at 530 (green, Figure 6), 532.5 (brown, Figure 6), and $534 \mathrm{eV}$ (blue, Figure 6). These results clearly demonstrate the presence of $\mathrm{Fe}_{2} \mathrm{O}_{3}$ and $\mathrm{FePO}_{4}$, which is in good agreement with $\mathrm{Fe} 2 \mathrm{p}_{3 / 2}$ [20]. The O-peak from 6-AHA is likely included in the $\mathrm{OH}$ peak at $532.5 \mathrm{eV}$, as the $\mathrm{O} 1$ s peak of organic molecules has been reported to appear at this energy level [25]. The $C$ 1s spectrum contain three components overall: (a) $285.5 \mathrm{eV}$ (brown, Figure 6) corresponding to the covalent $\mathrm{C}-\mathrm{C}$ bond of the adsorbed organic molecule [25] and carbon adsorbed from contaminants [22]; (b) $286 \mathrm{eV}$ (purple, Figure 6) associated with C-H bonds [26]; and (c) $288.9 \mathrm{eV}$ (green and blue, Figure 6) for carbon double-bonded to oxygen $\mathrm{C}=\mathrm{O}[22,23]$. The $\mathrm{P} 2 \mathrm{p}$ spectrum of the protective film consists of a single component with a binding energy value of $133.41 \mathrm{eV}$. This indicates that during ATP-6-AHA adsorption on the metal surface, the phosphate atoms are involved in the formation of the protective iron phosphate layer.

The $\mathrm{N}$ 1s spectrum observed for the ATP-6-AHA sample at $399.8 \mathrm{eV}$ shows the formation of the covalent $\mathrm{N}$ bonds of the organic pigment 6-AHA with carbon and $\mathrm{Fe}$ d-metals [26]. The $\mathrm{Na}^{+}$observed for both ATP and ATP-6-AHA at $1071 \mathrm{eV}$ corresponds to the $\mathrm{Na}^{+}$-ions resulting from the sodium chloride electrolyte solution.
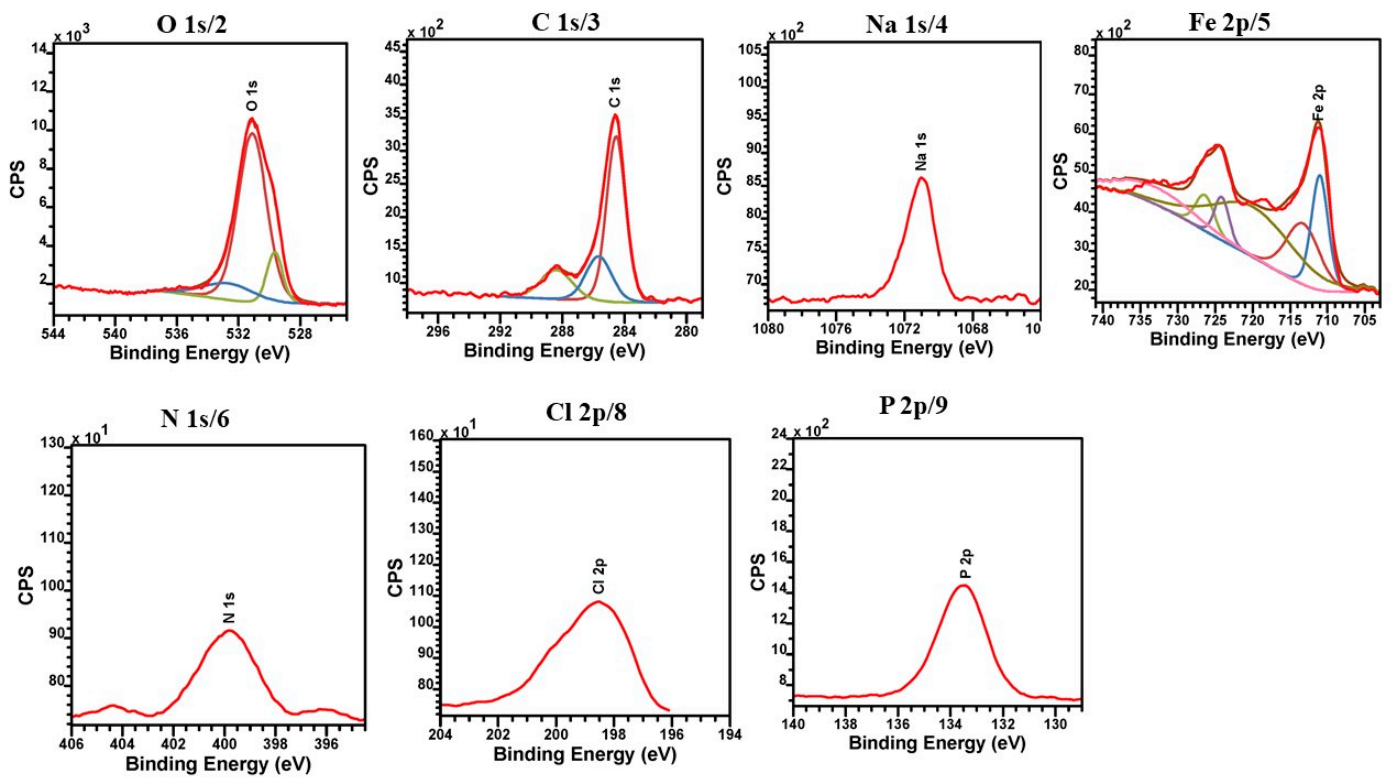

Figure 6. High resolution $\mathrm{O} 1 \mathrm{~s}, \mathrm{C} 1 \mathrm{~s}, \mathrm{Na} 1 \mathrm{~s}, \mathrm{Fe} 2 \mathrm{p}, \mathrm{N}$ 1s, Cl 2p, and P 2p XPS peaks obtained from the surface of S235 low-carbon steel substrate using ATP-6-AHA as an inhibitor after five days of treatment in 3.5\% NaCl solution (colors indicate typical bonds, details in the text).

\subsection{Morphology of Corrosion Products}

The SEM micrographs in Figure 7a show the surface of the S235 steel for the blank solution:

- A non-uniform film covering the $\mathrm{S} 235$ steel surface.

- Consists of particles in the form of flowery and sandy platelets, which are the typical shapes of crystallized iron oxides/hydroxides and oxyhydroxide $\mathrm{FeO}(\mathrm{OH})$ [27].

However, the protective film formed by ATP-6-AHA, as indicated in Figures $7 \mathrm{~b}$ and 8, is: 
- Slightly denser and more compact.

- It consists rather of broad plates such as crystals with different sizes that are evenly dispersed and a layered region.
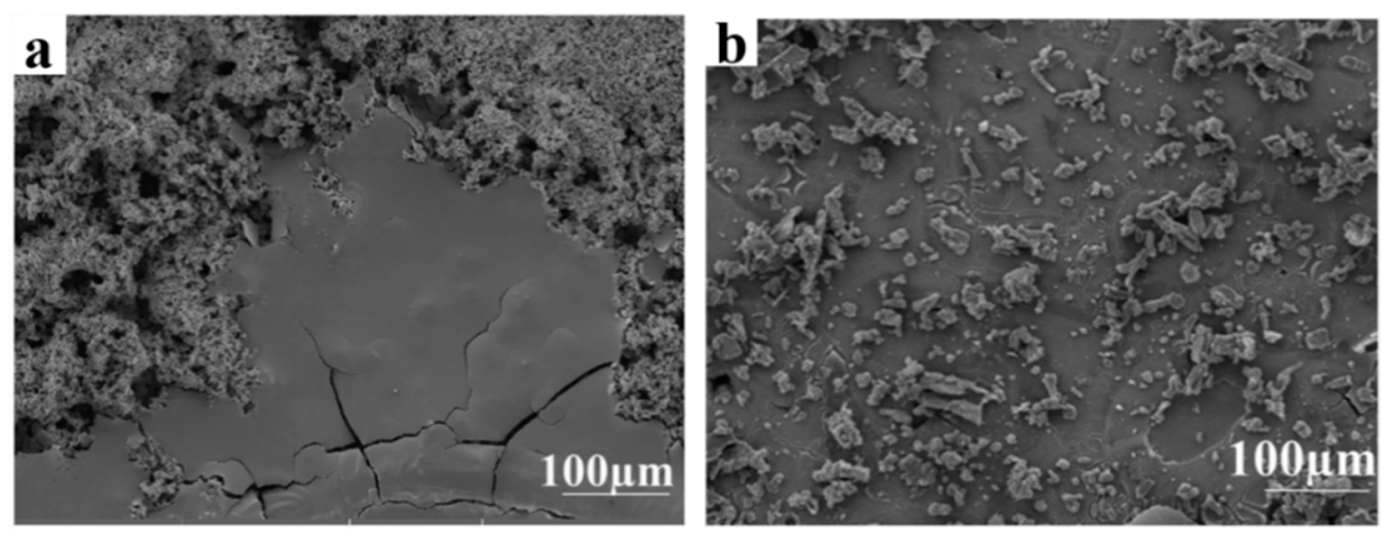

Figure 7. SEM morphology of S235 steel surface after five days of immersion in sodium chloride for the blank solution (a) and modified with ATP-6-AHA (b).

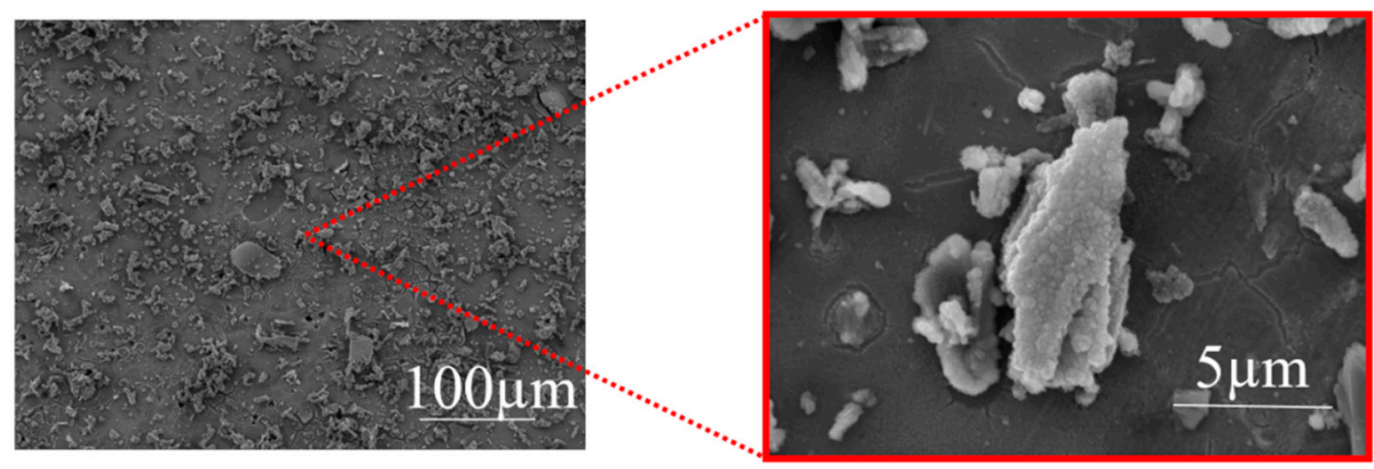

$\mathrm{Fe}$

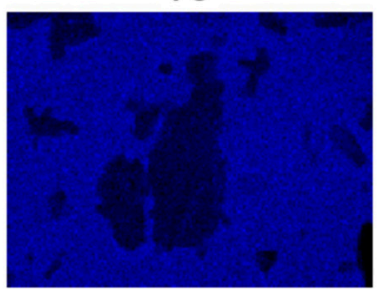

$\mathbf{P}$

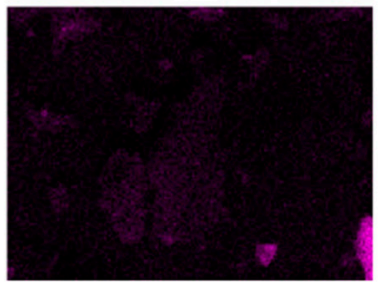

0

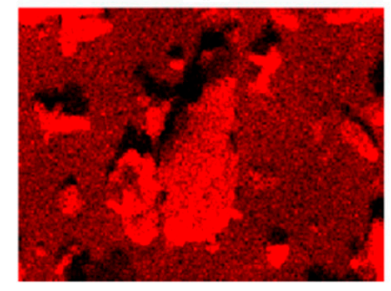

Figure 8. SEM image of S235 steel surface modified with ATP-6-AHA as the inhibitor after five days of immersion in $3.5 \%$ $\mathrm{NaCl}$ together with respective EDS maps $\mathrm{Fe}, \mathrm{P}$, and $\mathrm{O}$.

\section{Discussion}

In the presence of ATP-6-AHA, potentiodynamic polarization results in a $3.5 \mathrm{wt} . \%$ $\mathrm{NaCl}$ solution, which showed an appreciable decrement in anodic current density (Table 2). This result suggested that the addition of ATP-6-AHA would reduce the dissolution of the anode and that it would retard the oxygen reaction. Furthermore, the addition of ATP-6-AHA induced a small positive shift of E corr values, which is approximately $70 \mathrm{mV}$ higher than that in blank solution (Table 2).

For a comprehensive investigation on corrosion behavior, EIS was also performed in a $3.5 \mathrm{wt} . \% \mathrm{NaCl}$ solution. An assessment of the results shows that the addition of ATP-6-AHA increased the polarization resistance $R p$ by two times compared to the blank solution, which corresponds to an inhibition efficiency of $66 \%$. 
A protective film deposited on the steel surface was detected using XPS and SEM/EDX in the presence of ATP-6-AHA (Figures 6-8).

Through the synergistic effect of ATP and 6-AHA, the performance and corrosion resistance of carbon steel using ATP-6-AHA was improved. Additionally, the shortcomings of the high acidity of aluminum tripolyphosphate that leads to early rusting when used alone can be improved $[8,28,29]$. The neutralizing substances can regulate the $\mathrm{pH}$ of the inhibitor formula [8].

From the XPS and SEM analysis, it was found that the presence of 6-AHA and ATP in the solution creates a synergistic effect for the formation of an iron phosphate film on the steel surface. Consequently, it is possible to propose that the corrosion protection mechanism is associated with the combined efficiency of ATP and 6-AHA and involves several stages, as shown in Figure 9. The 6-AHA enhances the solubility and decreases the acidity of aluminum polyphosphate particles.

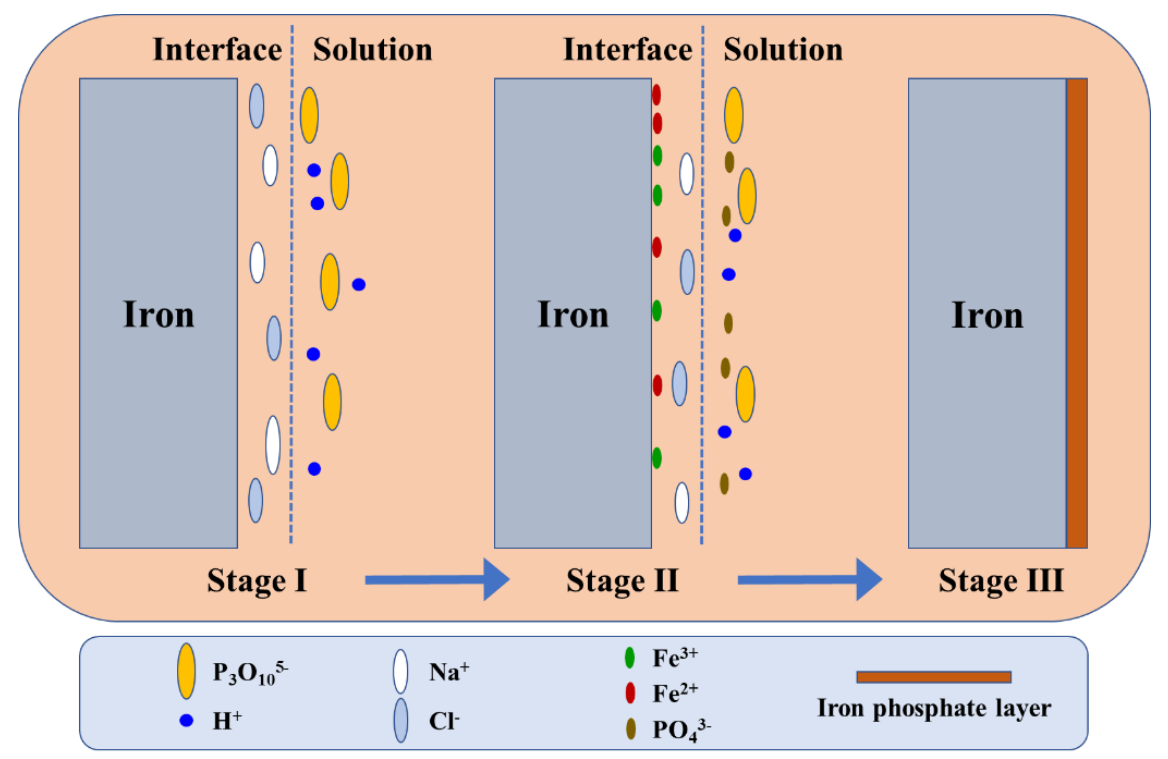

Figure 9. Proposed mechanism of ATP-6-AHA on S235 steel surface.

In the first stage in Figure 9, the decomposition of ATP-6-AHA led to the formation of $\mathrm{P}_{3} \mathrm{O}_{10}^{5-}$ and $\mathrm{H}^{+}$, as indicated in Equation (3). The dissolution of steel takes place, and the iron cations appear, as illustrated in Figure 9. In such acidic conditions, the 6-AHA may also act by decreasing the acidity, conducting the depolymerization of the tri-polyphosphate $\mathrm{P}_{3} \mathrm{O}_{10}^{5-}$ to $\mathrm{PO}_{4}{ }^{3-}$ orthophosphate particles (Equation (4)).

A protective film of iron phosphate on the steel surface (stage III), as supported by the experimental XPS and SEM findings, may be generated from Equations (5) and (6).

$$
\begin{gathered}
\mathrm{AlH}_{2} \mathrm{P}_{3} \mathrm{O}_{10} \rightarrow \mathrm{Al}^{3+}+2 \mathrm{H}^{+}+\mathrm{P}_{3} \mathrm{O}_{10}^{5-} \\
\mathrm{P}_{3} \mathrm{O}_{10}^{5-}+2 \mathrm{H}_{2} \mathrm{O} \rightarrow 4 \mathrm{H}^{+}+3 \mathrm{PO}_{4}^{3-} \\
\mathrm{Fe}^{2+}+\mathrm{Fe}^{3+}+\mathrm{P}_{3} \mathrm{O}_{10}^{5-} \rightarrow \mathrm{Fe}_{2} \mathrm{P}_{3} \mathrm{O}_{10} \\
\mathrm{Fe}^{3+}+\mathrm{PO}_{4}^{3-} \rightarrow \mathrm{FePO}_{4}
\end{gathered}
$$

Through taking advantage of various electrochemical methods, the corrosion inhibition performance of ATP-6-AHA in 3.5\% NaCl for S235 low-carbon steel can be defined in this work as the combined effect of phosphate anions, triphosphate anions, and 6-AHA organic molecules that leads to an iron phosphate film that blocks the corrosion sites. Thus, it was evident that both ATP and 6-AHA exhibited a synergistic effect that led to higher resistance. 


\section{Conclusions}

The corrosion of low carbon steel is a severe problem in industry. In the present study, the EIS and polarization results in the presence of ATP-6-AHA proved that ATP-6-AHA has a clear inhibitory ability in a $3.5 \% \mathrm{NaCl}$ solution.

The layered structure of ATP provides a loading ability for 6-AHA as an ecofriendly organic molecule that is able to provide an enhanced corrosion resistance. Nowadays, layered phosphate materials such as ATP exhibit promising potential for the corrosion inhibition of a metal or its alloy. Current research has greatly promoted the application of ATP-6-AHA as an inhibitor in nearly real environments (3.5\% $\mathrm{NaCl}$ solution). The deintercalation of 6-AHA from the host material was confirmed by means of the XRD and XRF techniques after the electrochemical test. Enhanced efficiency has already been shown to occur with an inhibitor concentration of $0.18 \mathrm{~g} / \mathrm{L}$ ATP-6-AHA.

In the present work, the inhibition mechanism of ATP-6-AHA was attributed to the synergistic effect of ATP and 6-AHA. The main conclusions can be summarized as follows:

- The decomposition of ATP-6-AHA can lead to the formation of $\mathrm{P}_{3} \mathrm{O}_{10}^{5-}$ and $\mathrm{H}^{+}$.

- The dissolution of steel takes place, and iron cations appear.

- The formation of the iron phosphate layer on the steel surface was confirmed by the current SEM and XPS analysis.

- The XPS and SEM analysis for ATP-6-AHA show that all of the P, C, O, and N atoms of the inhibitor are involved in the formation of the protective film, increasing its stability.

Author Contributions: C.H.: conceptualization, visualization, writing—original draft, methodology, review, and editing; A.A.A.: review and editing; N.S.: XPS analysis and review; M.M.: review and editing; M.D.: review; M.L.Z.: providing the techniques to perform analysis, review, and editing; R.H.: supervision and review; C.B.F.: visualization, supervision, review, and editing. All authors have read and agreed to the published version of the manuscript.

Funding: The financial support of the Materials Science, Energy and Nano-engineering department of Mohammed VI Polytechnic University is acknowledged.

Institutional Review Board Statement: Not applicable.

Informed Consent Statement: Not applicable.

Data Availability Statement: The data presented in this study are available on request from the corresponding author.

Acknowledgments: Parts of this research were performed during an internship at the HelmholtzZentrum hereon GmbH Geesthacht (HZG, Geestacht, Germany). Therefore, C.H. acknowledges the Institute of Surface Science for providing some experimental resources.

Conflicts of Interest: The authors declare no conflict of interest.

\section{References}

1. Haque, J.; Srivastava, V.; Verma, C.; Quraishi, A.M. Experimental and quantum chemical analysis of 2-amino-3-((4-((S)-2-amino-2carboxyethyl)-1H-imidazol-2-yl)thio) propionic acid as new and green corrosion inhibitor for mild steel in $1 \mathrm{M}$ hydrochloric acid solution. J. Mol. Liq. 2017, 225, 848-855. [CrossRef]

2. Refait, P.; Grolleau, A.-M.; Jeannin, M.; Rémazeilles, C.; Sabot, R. Corrosion of Carbon Steel in Marine Environments: Role of the Corrosion Product Layer. Corros. Mater. Degrad. 2020, 1, 198-218. [CrossRef]

3. Javadian, S.; Yousefi, A.; Neshati, J. Synergistic effect of mixed cationic and anionic surfactants on the corrosion inhibitor behavior of mild steel in 3.5\% NaCl. Appl. Surf. Sci. 2013, 285, 674-681. [CrossRef]

4. Dastgheib, A.; Attar, M.M.; Zarebidaki, A. Evaluation of Corrosion Inhibition of Mild Steel in $3.5 \mathrm{wt} \% \mathrm{NaCl} \mathrm{Solution} \mathrm{by} \mathrm{Cerium}$ Nitrate. Met. Mater. Int. 2020, 26, 1634-1642. [CrossRef]

5. Abrishami, S.; Naderi, R.; Ramezanzadeh, B. Fabrication and characterization of zinc acetylacetonate/Urtica Dioica leaves extract complex as an effective organic/inorganic hybrid corrosion inhibitive pigment for mild steel protection in chloride solution. Appl. Surf. Sci. 2018, 457, 487-496. [CrossRef]

6. Salehi, E.; Naderi, R.; Ramezanzadeh, B. Synthesis and characterization of an effective organic/inorganic hybrid green corrosion inhibitive complex based on zinc acetate/Urtica Dioica. Appl. Surf. Sci. 2017, 396, 1499-1514. [CrossRef] 
7. Song, W.; Yang, L.; Ma, X.; Liang, G. Effects of $\mathrm{CaO}$ and $\mathrm{MgO}$ on Anticorrosive Performance of Aluminum Dihydrogen Tripolyphosphate on Mild Steel. Ind. Eng. Chem. Res. 2018, 57, 13578-13585. [CrossRef]

8. Deyá, M.; di Sarli, A.R.; del Amo, B.; Romagnoli, R. Performance of anticorrosive coatings containing tripolyphosphates in aggressive environments. Ind. Eng. Chem. Res. 2008, 47, 7038-7047. [CrossRef]

9. Abdeli, M.; Ahmadi, N.P.; Khosroshahi, R.A. Corrosion inhibition of mild steel in hydrochloric acid by 6-aminohexanoic acid. Mater. Corros. 2010, 61, 147-151. [CrossRef]

10. Hejjaj, C.; Aghzzaf, A.A.; Bouali, I.; Hakkou, R.; Dahbi, M.; Fischer, C.B. Layered aluminum tri-polyphosphate as intercalation host for 6-aminohexanoic acid-Synthesis, characterization and application as corrosion protection inhibitor for low carbon steel. Corros. Sci. 2021, 181, 109239. [CrossRef]

11. Ding, Z.; Li, Y.Y.; Xu, M.R.; Hong, X.; Hong, S.X.; Dong, B. Electrochemical properties of aluminum tripolyphosphate modified chemically bonded phosphate ceramic anticorrosion coating. Constr. Build. Mater. 2020, 251, 118874. [CrossRef]

12. Lu, X.; Zuo, Y.; Zhao, X.; Tang, Y. The influence of aluminum tri-polyphosphate on the protective behavior of Mg-rich epoxy coating on AZ91D magnesium alloy. Electrochim. Acta 2013, 93, 53-64. [CrossRef]

13. Song, D.; Gao, J.; Shen, L.; Wan, H.; Li, X. The Influence of Aluminum Tripolyphosphate on the Protective Behavior of an Acrylic Water-Based Paint Applied to Rusty Steels. J. Chem. 2015, 2015, 618971. [CrossRef]

14. Pradityana, A.; Shahab, A.; Noerochim, L.; Susanti, D. Inhibition of Corrosion of Carbon Steel in $3.5 \% \mathrm{NaCl}$ Solution by Myrmecodia Pendans Extract. Int. J. Corros. 2016, 2016, 6058286. [CrossRef]

15. El-Haddad, M.N. Hydroxyethylcellulose used as an eco-friendly inhibitor for 1018 c-steel corrosion in $3.5 \% \mathrm{NaCl}$ solution. Carbohydr. Polym. 2014, 112, 595-602. [CrossRef]

16. Norouzi, B.; Yousefi, J.; Nami, N. Preparation of poly(naphthylamine-formaldehyde); Application as a new and an effective inhibitor of steel in hydrochloride acid solution. Russ. J. Appl. Chem. 2016, 89, 1879-1886. [CrossRef]

17. Rishi, S.K.; Kariuki, B.M.; Checker, N.J.; Godber, J.; Wright, A.J. Synthesis and crystal structure of $\mathrm{AlH}_{2} \mathrm{P}_{3} \mathrm{O}_{10} 2 \mathrm{HO}$; a new structure-type for layered acid phosphates. Chem. Commun. 2006, 747-749. [CrossRef]

18. Saifuddin, M.; Kim, S.; Aziz, A.; Kim, K.S. Mechanistic study of phosphorus adsorption onto Iron Z-A: Spectroscopic and experimental approach. Appl. Sci. 2019, 9, 4897. [CrossRef]

19. Luo, H.; Su, H.; Dong, C.; Li, X. Passivation and electrochemical behavior of 316L stainless steel in chlorinated simulated concrete pore solution. Appl. Surf. Sci. 2017, 400, 38-48. [CrossRef]

20. Yamashita, T.; Hayes, P. Analysis of XPS spectra of $\mathrm{Fe}^{2+}$ and $\mathrm{Fe}^{3+}$ ions in oxide materials. Appl. Surf. Sci. 2008, 254, 2441-2449. [CrossRef]

21. Eglin, M.; Rossi, A.; Spencer, N.D. X-ray photoelectron spectroscopy analysis of tribostressed samples in the presence of ZnDTP: A combinatorial approach. Tribol. Lett. 2003, 15, 199-209. [CrossRef]

22. Jiang, C.; Gao, Z.; Pan, H.; Cheng, X. The initiation and formation of a double-layer phosphate conversion coating on steel. Electrochem. Commun. 2020, 114, 106676. [CrossRef]

23. Ba, K.; Chahine, A.; Touhami, M.E.; Alauzun, J.G.; Manseri, A. Preparation and characterization of phosphate-nickel-titanium composite coatings obtained by sol-gel process for corrosion protection. SN Appl. Sci. 2020, 2, 350. [CrossRef]

24. Feliu, S.; Samaniego, A.; Bermudez, E.A.; El-Hadad, A.A.; Llorente, I.; Galván, J.C. Effect of native oxide film on commercial magnesium alloys substrates and carbonate conversion coating growth and corrosion resistance. Materials 2014, 7, 2534-2560. [CrossRef] [PubMed]

25. Njoku, D.I.; Li, Y.; Lgaz, H.; Oguzie, E.E. Dispersive adsorption of Xylopia aethiopica constituents on carbon steel in acid-chloride medium: A combined experimental and theoretical approach. J. Mol. Liq. 2018, 249, 371-388. [CrossRef]

26. Shabanova, I.N.; Chausov, F.F.; Naimushina, E.A.; Somov, N.V. XPS characterization of new corrosion inhibitor: Zinc aminophosphonate coordination comple. Surf. Interface Anal. 2014, 46, 750-753. [CrossRef]

27. de la Fuente, D.; Alcántara, J.; Chico, B.; Díaz, I.; Jiménez, J.A.; Morcillo, M. Characterisation of rust surfaces formed on mild steel exposed to marine atmospheres using XRD and SEM/Micro-Raman techniques. Corros. Sci. 2016, 110, 253-264. [CrossRef]

28. Feng, L.; Yuan, P. Corrosion protection mechanism of aluminum triphosphate modified by organic acids as a rust converter. Prog. Org. Coat. 2020, 140, 105508. [CrossRef]

29. Hejjaj, C.; Aghzzaf, A.A.; Scharnagl, N.; Zheludkevich, M.L.; Hakkou, R.; Fischer, C.B. Introduction of an innovative corrosionprotective alkyd steel coating based on a novel layered aluminum tripolyphosphate loaded with 6-amino hexanoic acid (ATP-6AHA). Prog. Org. Coat. 2021, 161, 106500. [CrossRef] 